\title{
PENERAPAN KONSEP ARSITEKTUR HI-TECH PADA BANGUNAN KANTOR SEWA DENGAN STUDI KASUS BANK OF CHINA
}

\author{
Pramesti Eka Braniati ${ }^{1}$, Wafirul Aqli ${ }^{2}$ \\ ${ }^{1}$ Universitas Muhammadiyah Jakarta, Program Studi Arsitektur \\ pramestieka.esti@gmail.com \\ ${ }^{2}$ Universitas Muhammadiyah Jakarta, Program Studi Arsitektur \\ wafirul.aqli@ftumj.ac.id
}

\begin{abstract}
Hi-tech architecture is an architectural style that in applying it develops technological sophistication. Hi-tech architecture is oriented toward the future with its characteristics, namely the exposed structure and the technology applied to buildings. To design buildings that implement prioritized hi-tech architecture needs to be implemented namely love, color, transparency, flexibility, and material vocabulary. The use of hi-tech architectural concepts in rental office planning to add value to buildings in order to compete with rental office buildings in general. The purpose of this research is to learn how to apply hi-tech architecture in rental office buildings using a Bank of China case study. This research was conducted by analyzing the hi-tech characteristics required by Richard Rogers in the Bank of China building. This analysis is carried out to draw conclusions that contain concepts and characteristics that indicate the application of hi-tech in rental office buildings.
\end{abstract}

Key Words: architechture, technology, hi-tech, building, office

\begin{abstract}
Abstrak : Arsitektur hi-tech merupakan gaya arsitektur yang dalam penerapannya mengembangkan kecanggihan teknologi. Arsitektur hi-tech berkiblat pada masa depan dengan ciri khasnya yaitu struktur yang diekspos dan teknologi yang diterapkan pada bangunan. Untuk mendesain bangunan yang menerapkan arsitektur hi-tech terdapat karakteristik yang perlu diimplementasikan yaitu exposed, love of colour, transparency, flexibility, dan material vocabulary. Penggunaan konsep arsitektur hi-tech pada perencanaan kantor sewa bertujuan untuk menambah nilai bangunan agar dapat bersaing dengan bangunan kantor sewa pada umumnya. Tujuan dari penelitian ini untuk mengetahui bagaimana penerapan arsitektur hi-tech pada bangunan kantor sewa dengan menggunakan studi kasus Bank of China. Penelitian ini dilakukan dengan menganalisis karakteristik arsitektur hi-tech yang perlu menurut Richard Rogers pada bangunan Bank of China. Analisis tersebut dilakukan untuk menarik kesimpulan berupa konsep dan karakteristik yang menunjukan penerapan arsitektur hi-tech pada bangunan kantor sewa.
\end{abstract}

Kata Kunci : arsitektur, teknologi, hi-tech, bangunan, kantor

\section{PENDAHULUAN}

Teknologi dapat membuat segala aktivitas manusia menjadi lebih mudah sehingga manusia mampu lebih bekerja lebih optimal. Penerapan teknologi digunakan pada berbagai aspek kehidupan manusia seperti bekerja dan berbisnis. Arsitektur hi-tech merupakan gaya arsitektur yang dalam penerapannya mengembangkan kecanggihan teknologi. Pada penerapannya arsitektur hi-tech berfokus pada pemaksimalan struktur bangunan untuk ditampilkan sebagai ornamen.

Istilah Arsitektur hi-tech pertama kali muncul pada tahun 70-an yang digunakan para arsitek untuk menyatakan teknologi alternatif. Sejalan dengan waktu istilah tersebut semakin sering digunakan, namun kemudian berubah karena arsitek-arsitek lebih memilih untuk menggunakan istilah teknologi tepat guna. Arsitektur hi-tech mempunyai makna yang berbeda dari industri hi-tech. Dimana dalam industri bermakna alat elektronik, computer, silicon chip, robot, dan sejenisnya, sedangkan dalam arsitektur bermakna langgam bangunan. (Ardiansyah, 2012)

Menurut Colin Davies hi-tech dalam arsitektur berarti gaya arsitektur yang berkiblat pada masa depan dengan ciri khasnya yaitu struktur yang diekspos dan teknologi yang diterapkan pada bangunan. Selain itu, menurut Charles Jenks, arsitektur hi-tech merupakan sebuah gaya yang idenya dianut dari konsep gerakan Modernisme. Tetapi dalam arsitektur hitech dikembangkan dengan ciri mengutamakan 
struktur dan memasukan unsur teknologi ke dalam bangunan untuk memberikan kenyamanan dan estetika. (Adhi W, 2012) Menurut Richard Rogers, penerapan hi-tech dalam arsitektur harus meliputi seluruh aspek pada bangunan. Untuk membuat perencanaan bangunan arsitektur hi-tech terdapat karakteristik yang perlu diimplementasikan yaitu exposed, love of colour, transparency, flexibility, dan material vocabulary. (Kawatu, 2017)

Bisnis merupakan kegiatan yang bersifat komersial. Desain facade dapat menjelaskan mengenai fungsi bangunan dan karakteristik yang muncul pada facade bangunan tersebut, sehingga desain facade dapat membentuk persepsi terhadap pengunjung. (Kosanti \& Dwiyanto, 2018) Mendesain facade bangunan sesuai fungsi tidak hanya akan menarik minat pengunjung untuk datang namun juga dapat menjadi nilai tambah terhadap bangunan tersebut. (Susanto et al., 2019) Selain itu, kebutuhan terhadap properti perkantoran identik dengan prestise dan perkembangan dari sebuah perusahaan. (Fauzan \& Dyah, 2019) Dalam penelitiannya (Yoniar \& Subagya, 2018) menyatakan bahwa penggunaan konsep arsitektur hi-tech pada perencanaan kantor sewa bertujuan untuk menambah nilai bangunan agar dapat bersaing dengan bangunan kantor sewa pada umumnya. Sehingga dengan adanya pernyataan tersebut dapat disimpulkan bahwa untuk menunjukkan citra yang menjual para pelaku bisnis membutuhkan kantor yang bangunannya memiliki nilai estetika yang tinggi untuk dapat meningkatkan prestise dari perusahaan mereka dan lebih mudah menarik calon penyewa.

Kemudian muncul pertanyaan mengenai penerapan arsitektur hi-tech pada bangunan kantor sewa yaitu bagaimana penerapan karakteristik arsitektur hi-tech pada bangunan kantor sewa. Oleh karena itu penelitian ini dilakukan untuk mengetahui penerapan karakteristik arsitektur hitech pada bangunan kantor sewa.

\section{METODOLOGI}

Pada penelitian ini jenis metode yang digunakan merupakan metode deskriptif kualitatif. Penelitian deskriptif merupakan penelitian yang dimulai dengan mengumpulkan data pendukung lalu kemudian menganalisa untuk mencari peranannya. (Arikunto \& Suharsimi, 2010) Sedangkan penelitian kualitatif merupakan penelitian yang tujuannya untuk memahami fakta tentang segala sesuatu pada objek penelitian. (Moleong, 2005) Jadi dapat disimpulkan metode deskriptif kualitatif merupakan metode pengolahan data lalu menganalisa faktor-faktor yang berkaitan dengan objek penelitian, kemudian hasilnya disajikan secara jelas. Sehingga penelitian ini dilakukan dengan cara mengumpulkan data yang berkaitan dengan teori arsitektur hi-tech dan kantor sewa kemudian melakukan observasi langsung terhadap studi kasus.

Proses analisis dilakukan dengan cara mengidentifikasi karakteristik arsitektur hi-tech yang perlu diimplementasikan pada bangunan menurut Richard Rogers yaitu exposed, love of colour, transparency, flexibility, dan material vocabulary pada bangunan kantor sewa. Analisis tersebut dilakukan untuk menarik kesimpulan berupa konsep dan karakteristik yang menunjukan penerapan arsitektur hi-tech pada bangunan kantor sewa.

Studi kasus yang digunakan pada penelitian ini adalah bangunan Bank of China. Bank of China dipilih karena bangunan tersebut merupakan salah satu bangunan gedung pencakar langit yang terkenal tertinggi keempat yang ada di Hong Kong. Bank of China juga memiliki bentuk bangunan yang asimetris sehingga dapat menjadi ikonik pada distrik setempat. Sehingga bangunan Bank of China menjadi salah satu refleksi pengaplikasian kecanggihan teknologi pada bangunan yang ada di Hong Kong. Bangunan ini letaknya berada di 1 Garden Road 14/F \& 52/F, Central Hong Kong.

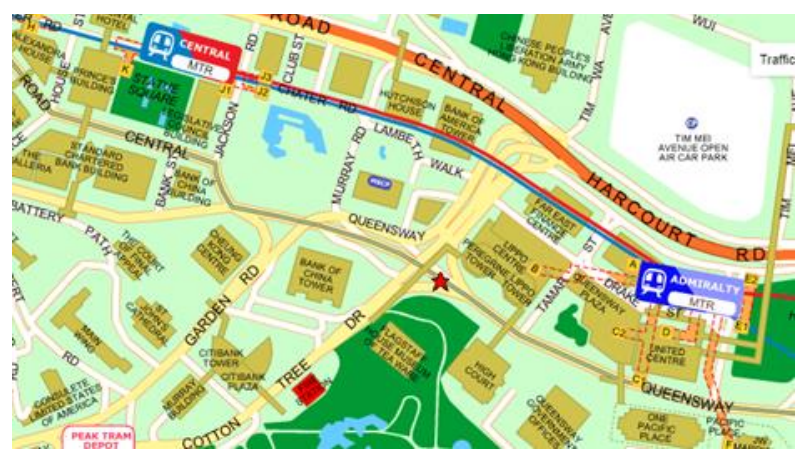

Gambar 1. Peta Bank of China

\section{HASIL DAN PEMBAHASAN \\ Exposed}

Arsitektur hi-tech mengutamakan kejelasan atau legibility dari sebuah bangunan. Exposed merupakan karakteristik yang dapat menekankan pada keterbukaan pada bangunan. Karaktersistik Exposed pada bangunan Bank of China diterapkan dengan penggunaan material yang dapat mengekspos bangunan. 
Bank of China menggunakan dua jenis material yang berbeda pada selubung bangunannya, material transparan dan material solid. Material transparan menggunakan kaca sedangkan material solidnya menggunakan beton. Namun, material yang paling dominan digunakan Bank of China adalah material kaca yang dapat dilihat pada gambar 2. Material kaca merupakan material yang bersifat transparan sehingga penggunaan material kaca pada bangunan dapat mengekspos bangunan tersebut. Sehingga bangunan Bank of China merupakan bangunan yang mengekspos bangunannya

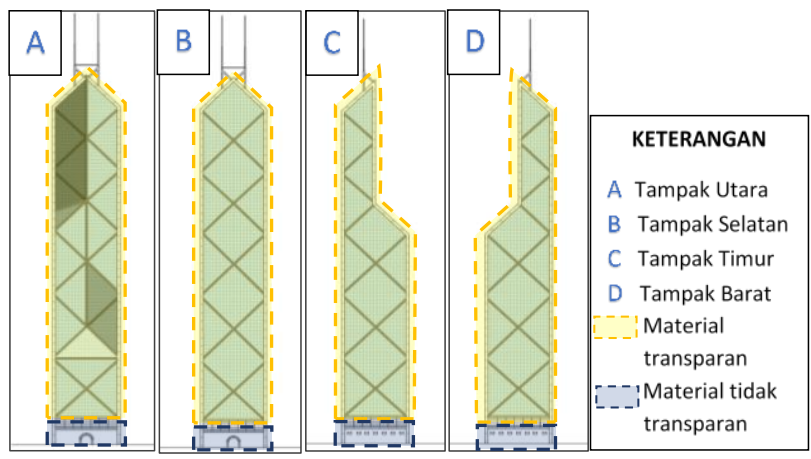

Gambar 2. Facade bangunan Bank of China

\section{Love of colour}

Salah satu bentuk dari legibility pada arsitektur hi-tech adalah dengan penggunaan warna. Hal tersebut akan memberi kontras pada bangunan terhadap lingkungannya. Warna-warna yang digunakan merupakan warna yang cerah dan terang seperti silver, putih, biru, merah dan kuning. Warna-warna cerah mewakilkan masa depan teknologi yang dapat berkembang secara terus-menerus. Karaktersistik Love of colour pada bangunan Bank of China diterapkan dengan penggunaan warna biru.

Warna biru tersebut dihasilkan dari penggunaan jenis material kaca reflektif pada selubung bangunannya. Kaca reflektif memiliki lapisan oksida logam yang berfungsi mengurangi transmisi energi panas sehingga memberikan kesejukan pada interior bangunannya. Lapisan tersebut berwarna perak sehingga dapat memantulkan pandangan dari luar. Oleh karena itu bangunan terlihat berwarna biru karena pantulan dari langit. Dengan memiliki bentuk masa prisma segitiga yang asimetris dan dibalut dengan material kaca, sekilas bangunan ini terlihat seperti berlian yang menyebabkan bangunan Bank of China menjadi bangunan yang ikonik. Hal tersebut berarti Bank of China menggunakan warna cerah sehingga menjadi kontras di lingkungan sekitarnya.

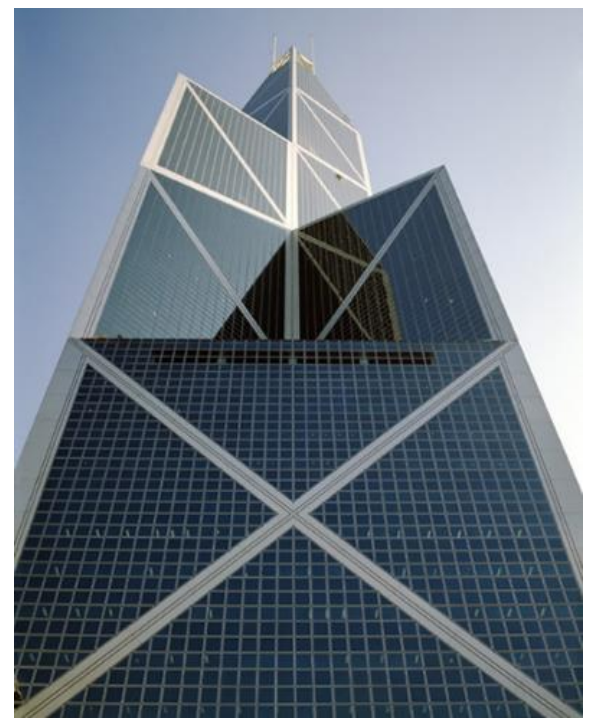

Gambar 3. Facade bangunan Bank of China

\section{Transparency}

Transparency merupakan karakteristik utama yang merefleksikan legibility pada bangunan, dengan penggunaan material yang transparan dan tembus cahaya. Karaktersistik Transparency pada bangunan Bank of China diterapkan dengan penggunaan material kaca secara maksimal.

Material kaca tidak hanya digunakan pada sisi selubung bangunannya saja, akan tetapi juga digunakan pada bagian atap bangunan seperti yang dapat dilihat pada gambar 4. Penggunaan material kaca pada atap bangunan dapat membantu pencahayaan alami masuk sehingga dapat meminimalkan penggunaan energi. Hal tersebut berarti Bank of China menggunakan material transparan secara maksimal.

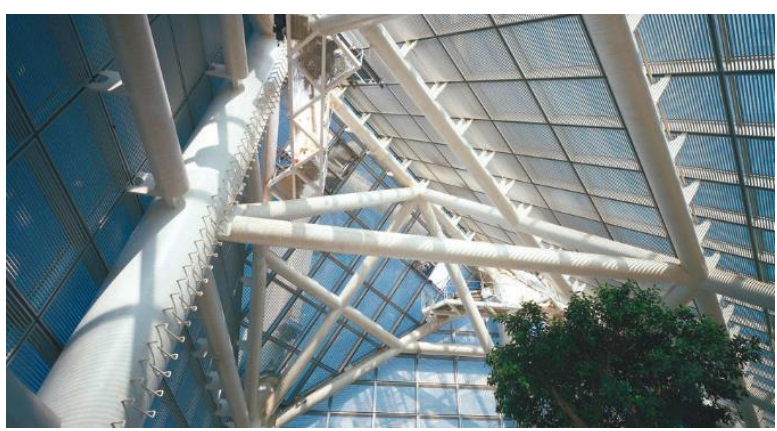

Gambar 4. Interior Bank of China 


\section{Flexibility}

Flexibility merupakan karakteristik yang mewakilkan masa depan pada arsitektur hi-tech. Artinya desain pada arsitektur hi-tech harus fleksibel dan memikirkan perubahan yang akan terjadi di masa yang akan datang. Karaktersistik Flexibility pada bangunan Bank of China diterapkan dengan penggunaan penataan ruang kantor jenis Open Plan System.

Open Plan System merupakan ruangan kerja yang memiliki ukuran yang besar sehingga dapat digunakan oleh beberapa pegawai untuk bekerja secara bersama-sama, biasanya terdapat sekat yang tidak permanen seperti partisi, furnitur ataupun tanaman. Hal tersebut dimaksudkan agar lebih luwes apabila diperlukan perubahan ruangan. (Perdana, 2019) Bank of China memiliki denah dengan letak service dibagian tengah dan sekelilingnya merupakan ruang kantor yang disewakan dengan penataan ruang kerja Open Plan System. Sekat-sekat antar ruang terbuat dari partisi tidak permanen. Hal tersebut berarti penataan ruang Bank of China bersifat fleksibel.

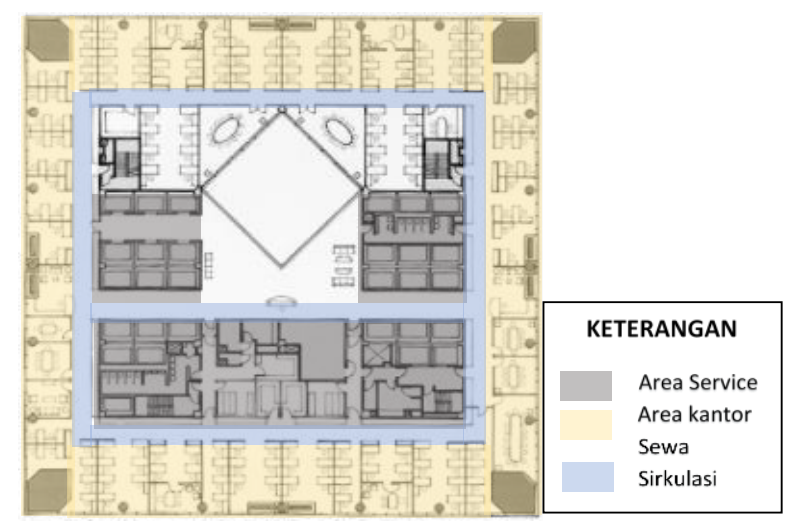

Gambar 5. Denah bangunan Bank of China

\section{Material Vocabulary}

Material Vocabulary merupakan karakteristik yang dilihat dengan penggunaan material yang merepsresentasikan arsitektur dari sebuah bangunan. Material yang menjadi karakteristik hi-tech merupakan material yang bersifat lightweight material. Karakteristik Material Vocabulary pada Bangunan Bank of China diterapkan dengan penggunaan lightweight material jenis baja.

Material baja tersebut digunakan pada struktur brached frame bangunan. Struktur brached frame merupakan struktur yang memiliki bracing berbahan material baja yang berfungsi menahan kekuatan struktur bangunan dari angin. Selain itu penggunaan baja pada Bank of China ini menjadi pengekspresian struktur pada facade bangunannya. Hal tersebut berarti Bank of China menggunakan Material Vocabulary pada bangunannya untuk merepsresentasikan arsitektur hi-tech.

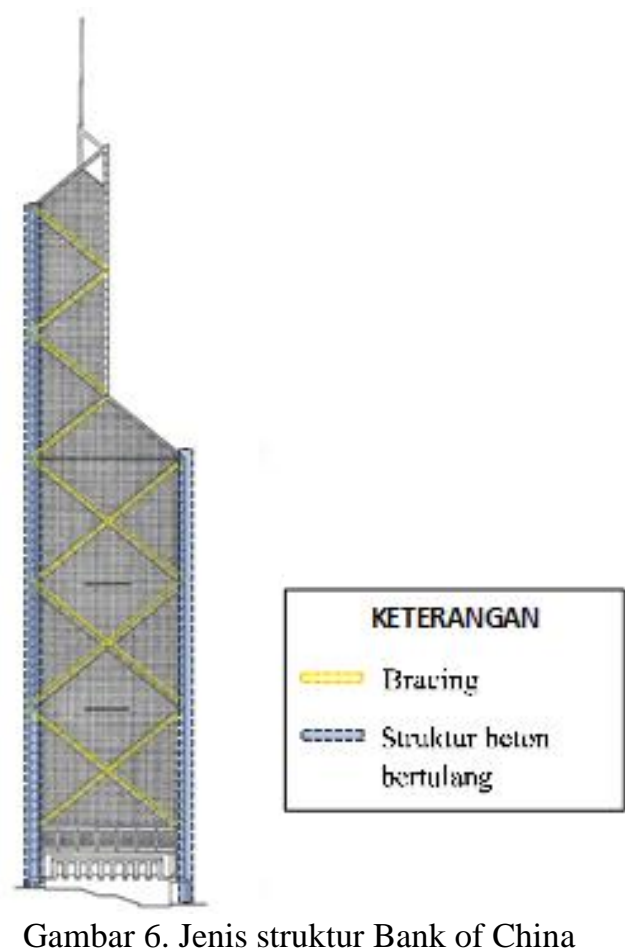

\section{PENUTUP \\ Simpulan}

Penerapan arsitektur hi-tech pada bangunan kantor sewa dapat dilakukan dengan menerapkan karakteristik arsitektur hi-tech yaitu exposed, love of colour, transparency, flexibility, dan material vocabulary.

Karakteristik exposed diterapkan pada bangunan kantor sewa dengan penggunaan material yang dapat menunjukan keterbukaan pada bangunan misalnya penggunaan material kaca pada selubung bangunannya.

Love of colour diterapkan pada bangunan kantor sewa dengan menerapkan warna-warna cerah yang dapat menjadi kontras pada bangunan dengan lingkungan sekitarnya. Warna-warna yang dapat aplikasikan adalah warna silver, putih, biru, merah dan kuning.

Transparency diterapkan pada bangunan kantor sewa dengan mendesain bangunan dengan penggunaan material kaca secara maksimal. Penggunaan kaca tidak hanya dapat digunakan untuk sisi bangunan saja tetapi juga pada bagian atap bangunan. Hal tersebut juga memiliki keuntungan untuk menghemat penggunaan energi Flexibility diterapkan pada bangunan kantor sewa dengan mendesain denah bangunan 
dengan penataan ruang yang fleksibel, dapat memungkinkan terjadinya perubahan di masa yang akan datang. Salah satu penataan ruang yang dapat digunakan merupakan penataan ruang Open Plan System.

Material Vocabulary diterapkan pada bangunan kantor sewa dengan penggunaan lightweight material sebagai pengekspresian struktur arsitektur hi-tech. Jenis lightweight material yang dapat digunakan adalah material baja.

\section{Saran}

Diharapkan adanya penelitian selanjutnya mengenai arsitektur hi-tech dengan studi kasus bangunan kantor sewa yang berada di Indonesia atau penelitian mengenai perencanaan bangunan kantor sewa dengan penerapan arsitektur hi-tech.

\section{DAFTAR PUSTAKA}

Adhi W, A. (2012). Rental Office di Semarang dengan Penekanan Arsitektur Hi-Tech. 3.

Ardiansyah. (2012). Analisis Rancangan Norman Foster Pada Bangunan Chek Lap Kok Airport (Hongkong) Dalam Konteks Arsitektur High-Tech. 37.

Arikunto, \& Suharsimi. (2010). Suatu Pendekatan Praktik. Rineka Cipta.

Fauzan, M., \& Dyah, A. (2019). Perancangan Rental Office Di Jakarta Dengan Penerapan Arsitektur Futuristik. Maestro, 2(1), 109115.

Kawatu, F. E. (2017). Aplikasi Bangunan HighTech Dalam Teori Perancangan Richard Rogers. 32-37.

Kosanti, A. I., \& Dwiyanto, A. (2018). Kajian Terhadap Fasad Mall Di Semarang.

Moleong, L. J. (2005). Metodologi Penelitian Kualitatif. Remaja Rosdakarya.

Perdana, C. S. (2019). Analisis Produktivitas Pegawai Dalan Desain Open-Plan di Perpustakaan Universitas Airlangga.

Susanto, A., Arum, R., \& Rejoni, R. (2019). Perancangan Pusat Peragaan Iptek Dengan Pendekatan Arsitektur High Tech Di Lampung. 94.

Yoniar, G. A., \& Subagya, K. (2018). Perencanaan Rental Office Di Bsd City Cisauk,Kabupaten Tangerang Dengan 